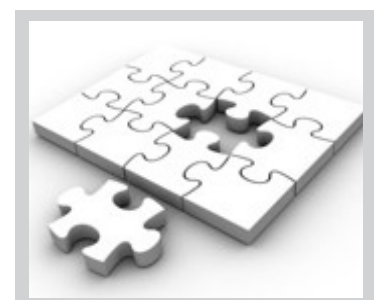

In an effort to facilitate the selection of appropriate peer reviewers for the Journal of Medicinal Plants for Economic Development, we ask that you take a moment to update your electronic portfolio on http:/ / www.jomped.co.za for our files, allowing us better access to your areas of interest and expertise, in order to match reviewers with submitted manuscripts.

If you would like to become a reviewer, please visit the journal website and register as a reviewer.

To access your details on the website, you will need to follow these steps:

1. Log into the online journal at http://www. jomped.co.za

2. In your 'user home' [http://www.jomped. co.za/index.php/jomped/ user] select 'edit my profile' under the heading 'my account' and insert all relevant details, bio statement and reviewing interest.

3. It is good practice as a reviewer to update your personal details regularly to ensure contact with you throughout your professional term as reviewer to the Journal of Medicinal Plants for Economic Development.

Please do not hesitate to contact us if you require assistance in performing this task.

\section{Publisher:}

publishing@aosis.co.za

Tel: +27 219752602

Fax: +27 219754635

\title{
Acknowledgement to reviewers
}

The editorial team of the Journal of Medicinal Plants for Economic Development recognises the value and importance of the peer reviewer in the overall publication process - not only in shaping the individual manuscript, but also in shaping the credibility and reputation of our journal.

We are committed to the timely publication of all original, innovative contributions submitted for publication. As such, the identification and selection of reviewers who have expertise and interest in the topics appropriate to each manuscript are essential elements in ensuring a timely, productive peer review process.

We would like to take this opportunity to thank all reviewers who participated in shaping this volume of the Journal of Medicinal Plants for Economic Development:

\author{
Adeolu A. Adedapo \\ Alfred Maroyi \\ Beauty E. Omoruyi \\ Charles Ntahonshikira \\ Gloria A. Otunola \\ Joshua O. Kayode \\ Matthew O. Oyeyemi \\ Mojeed O. Liasu \\ Musa T. Yakubu
}

We appreciate the time taken to perform your review successfully.

\author{
Olaoluwa T. Adeymi \\ Olubukola S. Olorunnisola \\ Olubunmi J. Sharaibi \\ Olukemi Odukoya \\ Samuel W. Odeyemi \\ Sunday O. Oyedemi \\ Taofik O. Sunmonu \\ Wilfred O. Mbeng
}

